\title{
Automated Assessment of Conditioning Parameters for Context and Cued Fear in Mice
}

\author{
Angelo Contarino, ${ }^{1}$ Leonardo Baca, Arthur Kennelly, and Lisa H. Gold ${ }^{2}$ \\ The Scripps Research Institute, Department of Neuropharmacology, La Jolla, California 92037, USA
}

\begin{abstract}
A behavioral technique often used to evaluate the cognitive performance of rats and mice is the fear conditioning paradigm. During conditioned fear experiments, freezing responses shown by rodents after exposure to environmental stimuli previously paired to an aversive experience provide a behavioral index of the animal's associative abilities. The present study examined the ability of a computer-controlled automated Freeze Monitor system for recording immobility behavior in mice. The sensitivity of the automated procedure to detect group differences caused by the application of various training protocols was also evaluated. Statistical analyses revealed significant positive correlations between immobility scores obtained with the automated apparatus and hand-scored data collected by a continuous or a time-sampling method. Behavioral patterns recorded by the computerized system were very similar to those obtained by the hand-scoring methods adopted. In particular, during context testing, exposure to environmental stimuli previously paired with a mild foot shock (unconditioned stimulus [US]) evoked increased immobility behavior in mice conditioned with the US compared with levels of immobility displayed by mice previously confined to the same contextual stimuli without receiving the US. Moreover, although during conditioned stimulus (CS) testing, mice previously exposed to the US displayed high levels of immobility when confined to environmental cues much different from those paired with the US (contextual fear generalization), both hand-scored and automated results revealed the effect of CS-US pairing (increased immobility) only in mice trained to associate the two stimuli (paired group) but not in mice exposed to both CS and US separated by a 40-sec time interval (unpaired group) or in mice receiving only the US (US group) during conditioning sessions. Overall, the results show associative conditioning measured in an automated apparatus and highlight the utility of obtaining both latency as well as beam interruption parameters.
\end{abstract}

In the past two decades, numerous studies have been devoted to the investigation of the neural mechanisms subserving learning and memory processes. Rodent studies have proved very useful for the understanding of brain pathways underlying cognition. Analysis of transgenic mice with targeted gene mutations has further allowed delineation of the role for specific genes and proteins in learning and memory processes (Abeliovich et al. 1993; Bourtchuladze et al. 1994; Aiba et al. 1994).

One often used behavioral technique to assess learning and memory abilities of rats and mice is the fear conditioning paradigm (Wehner and Silva 1996). Typically, during a fear conditioning experiment, animals are exposed to an aversive stimulus (unconditioned stimulus [US]), usually a mild foot shock, in the presence of specific environmental stimuli (visual, tactile, auditory, etc.). Subsequently, fearelicited freezing responses evoked by contact with stimuli present during US exposure provide a measure of the ani-

Present addresses: ${ }^{1}$ Dipartimento di Farmacologia ed Anestesiologia, Largo Meneghetti 2, 35131 Padova, Italy; ${ }^{2}$ Pharmacia Corporation, mail code 7251-209-405, 301 Henrietta Street, Kalamazoo, MI 49007, USA.

${ }^{1}$ Corresponding author at present address.

E-MAIL angelo.contarino@unipd.it; FAX +39-049-8275093.

Article and publication are at http://www.learnmem.org/cgi/doi/ 10.1101/lm.43002. mal's ability to remember those stimuli previously associated with the US. Classical conditioning mechanisms are thought to underlie freezing responses displayed by rodents during fear conditioning experiments (Fanselow 2000).

Although initially validated for use in rats (Fanselow 1990; Phillips and LeDoux 1992), the increasing availability of mutant mouse models has promoted the need to adapt the fear conditioning paradigm for use in mice. Recently, this technique has gained popularity to assess learning and memory processes in several inbred and mutant mouse strains (Owen et al. 1997; Logue et al. 1997; Silva et al. 1997).

To date, most fear conditioning studies have quantified freezing behavior with tedious and labor-intensive visual observation methods of recording. Visual observation techniques may be influenced by confounding variables, such as experimenter biases, which are absent during automated measurement of rodent behavior (LoLordo and Ross 1990; Sanberg et al. 1984, 1985). Recently, a few studies were performed to assess the ability of new computer-assisted automated procedures to detect freezing behavior of rats and mice (Valentinuzzi et al. 1998; Richmond et al. 1998; Anagnostaras et al. 2000). In the latter studies, visual observation-derived data significantly correlated with automated measurements of immobility, thus demonstrating the ability

LEARNING \& MEMORY 9:89-96 @ 2002 by Cold Spring Harbor Laboratory Press ISSN1072-0502/02 \$5.00

$$
\begin{array}{lllllllllllllll}
\text { L } & E & A & R & N & I & N & G & \mathbf{Q} & M & E & M & O & R & Y
\end{array}
$$




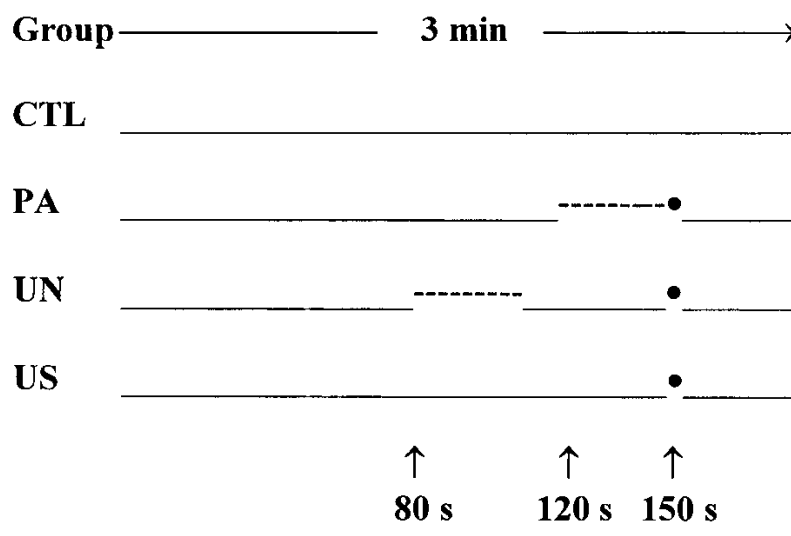

Figure 1 Scheme showing experimental manipulations applied to the four different groups of mice (CTL, PA, UN, and US) during the conditioning sessions. Numbers below the arrows indicate time (sec) into the session when CS and US were delivered. .....: CS, auditory tone $(80 \mathrm{~dB}, 3000 \mathrm{~Hz}, 30 \mathrm{sec})$; $\bullet$ : US, foot shock $(0.7 \mathrm{~mA}$, $2 \mathrm{sec})$.

of these computerized procedures to reliably record freezing behavior. In addition, automated scoring could provide a variety of additional behavioral indices, such as unconditioned reaction to foot shock and baseline locomotor activity, which are difficult to quantitate by human observers.

The present work was performed to examine the ability of an automated Freeze Monitor system to reliably record immobility behavior displayed by mice subjected to a variety of experimental manipulations. During conditioning sessions, mice were exposed to a mild foot shock (US) and an auditory cue (conditioned stimulus, CS) with different protocols for presentation of the two stimuli. On the next day, to discern between levels of immobility caused by repeated exposure to the same environmental stimuli (habituation processes) and immobility behavior caused by US exposure, contextual fear in mice previously conditioned with the US was compared with mice that had not been exposed to the aversive US during conditioning sessions (control group). Moreover (extending previous studies examining the ability of automated procedures to reliably record freezing behavior in mice), during CS testing, specificity of immobility responses to the CS was evaluated by comparing the per- formance of mice previously conditioned with a single CSUS pairing (paired group) to that displayed by mice receiving both CS and US separated by a 40-sec time interval (unpaired group) or mice exposed only to the US (US group) during conditioning sessions (Fig. 1). Concomitant with automated data acquisition, mouse behavior was also recorded on videotapes and later scored by a trained experimenter. Correlation analyses between experimenter-derived data and results derived from the multiple automated parameters were performed to determine if the automated apparatus could reliably record immobility behavior in mice as well as detect expected group differences caused by the various training protocols used. $\mathrm{C} 57 \mathrm{BL} / 6 \mathrm{~J}$ mice were used here because this inbred strain shows consistent freezing responses when exposed to threatening stimuli and has been extensively used in the generation of transgenic mice (Gold 1996; Crawley et al. 1997). To extend previous fearconditioning studies that used time-sampling procedures, experimenter-derived data by visual observation were collected by use of both continuous and time-sampling handscored measurements of animal behavior during the entire test session.

\section{RESULTS}

Table 1 shows correlation coefficients ( $r$ values) between hand-scored data and results obtained with the different automated parameters collected during context and CS tests. All latency and BI parameters showed a significant correlation with the data collected by both continuous and time-sampling methods of hand scoring $(P<.0001)$. Correlation coefficients ranged between 0.575 and 0.861 . Overall, automated results showed higher correlation coefficients with time sampling than continuous hand scores. The automated measure of $\mathrm{BI}$, which represents the functional opposite of freezing, negatively correlated with the hand-scored data. Linear regression analysis was also used to calculate $r^{2}$ for the relationship between hand-scored (continuous and time sampling) and the automated latency to $\mathrm{BI}$ measures. In all cases the slope of the line was significantly nonzero (data not shown), and the $r^{2}$ for the comparison of automated BI latencies with time sampling was greater than

Table 1. Pearson's Correlation Coefficients ( $\mathrm{r}$ Values) Between Hand-Scored (Continuous or Time-Sampling) and Computer-Derived Parameters (Latencies to and Number of Beam Interruptions, BI)

\begin{tabular}{lrrrrrrr}
\hline & \multicolumn{3}{c}{ Continuous hand scores } & & & \multicolumn{3}{c}{ Time-sampling hand scores } \\
\cline { 2 - 3 } Computer parameters & Context & pre-CS & CS & & Context & pre-CS & CS \\
\hline Latency 1st BI & 0.709 & 0.575 & 0.744 & & 0.785 & 0.703 & 0.790 \\
Latency 2nd BI & 0.766 & 0.643 & 0.705 & & 0.857 & 0.757 & 0.795 \\
Latency 3rd BI & 0.760 & 0.689 & 0.663 & & 0.861 & 0.770 & 0.785 \\
Beam interruptions & -0.700 & -0.730 & -0.750 & -0.769 & -0.786 & -0.795 \\
\hline
\end{tabular}

Collected during the context (5 min) and the two phases of the CS test, that is, pre-CS ( $3 \mathrm{~min}$ ) and CS ( $3 \mathrm{~min})$.

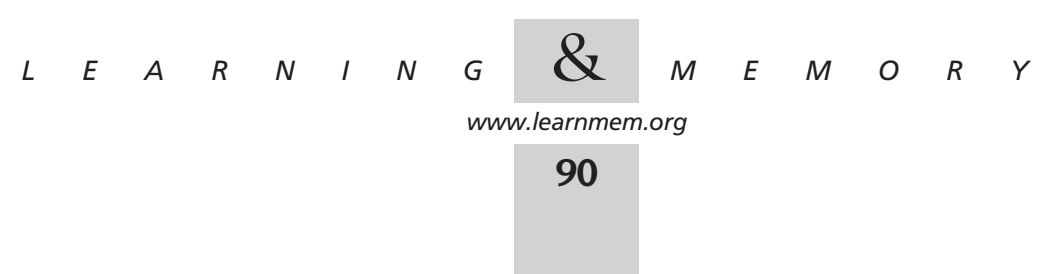


the comparison with the continuous hand-scored data. For latency to 1st BI compared with the continuous handscored data, $r^{2}$ values are $0.541,0.331$, and 0.555 for context, pre-CS, and CS periods, respectively. For latency to $1 \mathrm{st}$ $\mathrm{BI}$ compared with the time-sampling hand-scored data, the $r^{2}$ values are $0.618,0.495$, and 0.625 for context, pre-CS, and CS periods, respectively. Hand-scored and latency 1 st BI results were used for graphical purposes. Latency 1st BI data were chosen because, compared to latency 2nd and 3rd BI, the absolute amount of immobility behavior detected by this computerized parameter more closely resembled freezing behavior as assessed by the hand-scored methods.

\section{Conditioning Sessions}

Levels of unconditioned locomotor activity after initial exposure to the conditioning chamber were examined with the data collected during the first minute of the training sessions, a time period in which neither CS nor US were applied. Hand-scored, as well as all latency results, revealed very low levels of immobility, making it difficult to carry out group comparisons. Thus, the automated BI parameter was used to evaluate motor performance of the four different groups of mice. Cumulative BI during the first minute of training were: $\mathrm{CTL}=299.4 \pm 8.0, \mathrm{PA}=314.1 \pm 8.1$, $\mathrm{UN}=315.5 \pm 6.6$, and $\mathrm{US}=303.1 \pm 6.5$; mean $\pm \mathrm{SEM}$. No group difference was observed $(F[3,38]=1.12, P=.35)$. After US exposure, latency 1st BI results did not reveal any group effect $(F[3,38]=1.07, P=0.37$; Fig. $2 \mathrm{~A})$; however, a significant group effect was observed for continuous $(F[3,38]=7.17, P<.001)$ and time-sampling $(F[3,38]=3.31$, $P<.05$ ) hand scores (Fig. 2, B and C). Post hoc analyses of hand-scored data showed that during the 30-sec time interval after US delivery, the PA, UN, and US groups spent more time freezing than did the CTL mice $(P<.05)$. No difference was observed among the PA, UN, and US groups. Similar to latency 1st $\mathrm{BI}$ results, latency 2nd $\mathrm{BI}(F[3,38]=1.49$, $P=0.23)$ and latency $3 \mathrm{rd} \mathrm{BI}(F[3,38]=2.18, P=0.10) \mathrm{did}$ not reveal any significant effect of US exposure (data not shown). However, among the automated measures a significant group effect was obtained with the BI parameter $(F[3,38]=6.26, P<.005)$. After US delivery, PA, UN, and US mice made fewer BI than the CTL group $(P<.05$; Fig. 3$)$. No significant difference was observed among the PA, UN, and US groups.

\section{Context Test}

Reexposure to the conditioning chamber $24 \mathrm{~h}$ after the training sessions resulted in increased levels of immobility behavior in the mice previously exposed to the aversive US. Evaluation of latency 1st BI data revealed a group effect $(F[3,38]=8.44, \quad P<.0005)$, a time effect $(F[4,152]=$ $3.13, P<.05)$, but no group $\times$ time interaction effect $(F[12,152]=1.36, P=.19)$. Post hoc analyses showed that

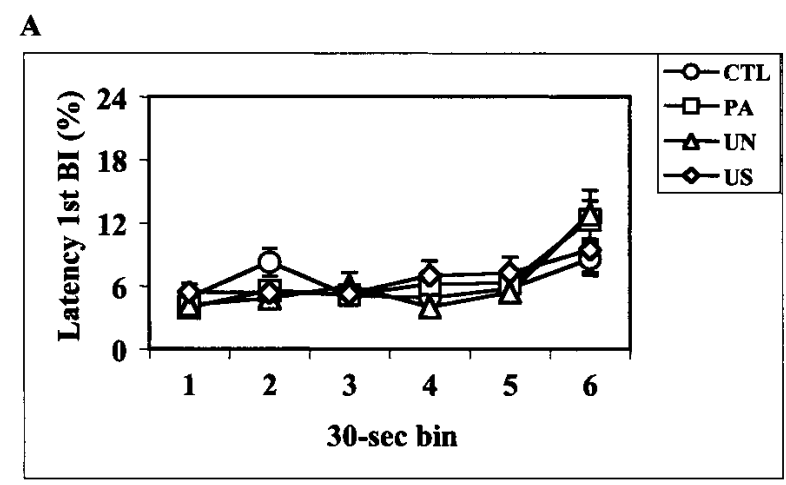

B

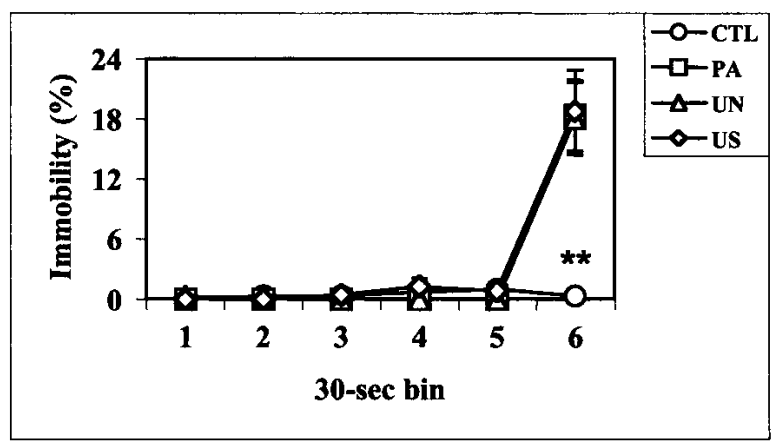

C

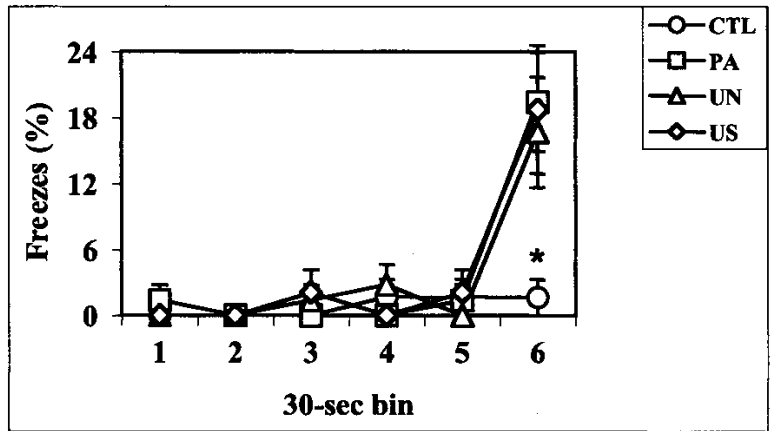

Figure 2 Conditioning sessions. Percentage of immobility behavior displayed by control (CTL, $n=10$ ), paired (PA, $n=12$ ), unpaired ( $U N, n=12)$, and $U S$ exposure only ( $U S, n=8)$ mice during consecutive $30-$ sec time intervals as assessed by latency 1 st BI $(A)$ and the continuous $(B)$ and time-sampling $(C)$ methods of hand scoring. PA, UN, and US mice were exposed to the foot-shock US (2 sec, $0.7 \mathrm{~mA}$ ) $148 \mathrm{sec}$ after the session started (end of the 5th bin). Hand-scored data show that during the last $30-\mathrm{sec}$ time interval (6th bin) PA, UN, and US mice spent more time freezing than the CTL group. ${ }^{*} P<0.05,{ }^{* *} P<0.005$ versus $\mathrm{PA}, \mathrm{UN}$, and US groups at the same time point (Newman-Keuls post hoc test).

mice exposed to the aversive US during the conditioning sessions displayed increased levels of immobility compared with the CTL group $(P<.005$; Fig. $4 \mathrm{~A})$, whereas no difference was observed among the PA, UN, and US groups. La-

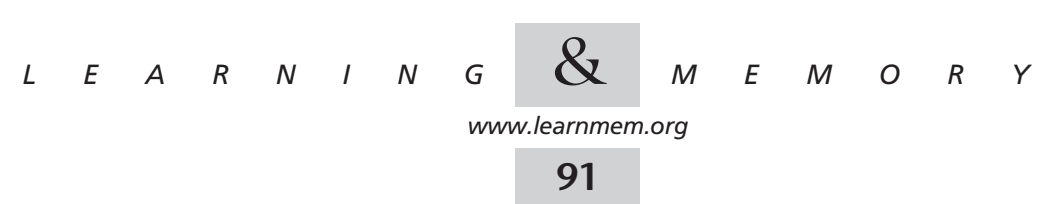




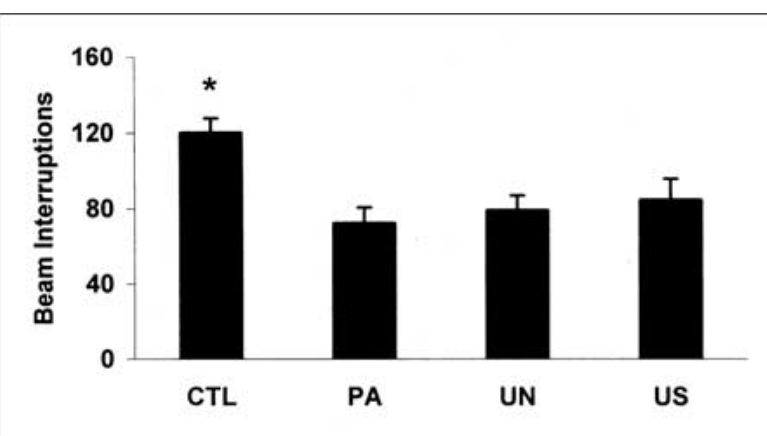

Figure 3 Conditioning sessions. Number of beam interruptions recorded in control $(C T L, n=10)$, paired $(P A, n=12)$, unpaired $(U N, n=12)$, and $U S$ exposure only $(U S, n=8)$ groups during the last 30 -sec time interval after foot-shock exposure. ${ }^{*} P<.05$ versus PA, UN, and US groups (Newman-Keuls post hoc test).

tency 2nd and 3rd BI data provided findings comparable to those obtained with latency 1st BI (data not shown). BI results also revealed a group effect $(F[3,38]=5.42$, $P<.005)$, a time effect $(F[4,152]=5.02, P<.001)$, but no group $\times$ time interaction effect $(F[12,152]=0.93$, $P=0.51)$. The PA, UN, and US groups made fewer BI than CTL mice $(P<.01$; data not shown). No difference was observed among the PA, UN, and US groups. Similar to automated results, continuous hand-scored data revealed a significant group effect $(F[3,38]=7.91, P<.0005)$, no effect of time $(F(4,152)=1.78, P=0.13]$, and no group $\times$ time interaction $(F[12,152]=1.26, P=0.24)$. Post hoc group comparisons showed that during the 5-min context test, PA, UN, and US mice displayed increased levels of freezing behavior compared with the CTL group $(P<.005$; Fig. $4 \mathrm{~B}$ ). No significant difference was detected among the PA, UN, and US groups. Likewise, time-sampling data revealed a significant group effect $(F[3,38]=14.59$, $P<.0001)$, a time effect $(F[4,152]=4.76, P<.005)$, and no group $\times$ time interaction $(F[12,152]=0.99, P=0.46)$. Group comparisons showed that PA, UN, and US mice displayed increased levels of freezing behavior compared with the CTL group $(P<.0005$; Fig. $4 \mathrm{C})$. No significant difference was detected among the PA, UN, and US groups. Finally, analysis of latency 1st BI results derived from the CTL group revealed higher levels of immobility during the context compared with the training sessions (training: $3.7 \pm 0.2$ sec, context: $5.7 \pm 0.7 \mathrm{sec}$; $\mathrm{t}(9)=2.91, P<.05$; mean value/ minute \pm SEM). Analysis of all other automated parameters, as well as hand-scored data, revealed similar findings, indicating some degree of habituation to the testing chamber in mice never presented with the US but repeatedly exposed to the same environmental stimuli. Thus, during contexttest sessions, results obtained with both hand-scored methods used here were very similar to those provided by the multiple automated parameters. Particularly, increased levels of freezing behavior were detected in mice previously trained to associate specific environmental (contextual) stimuli with the aversive US experience.

\section{CS Test}

Latency 1st BI results yielded a group effect $(F[3,38]=5.39$, $P<.005)$, a time effect $(F[5,190]=15.19, \quad P<.0001)$, and a group $\times$ time interaction effect $(F[15,190]=2.57$,

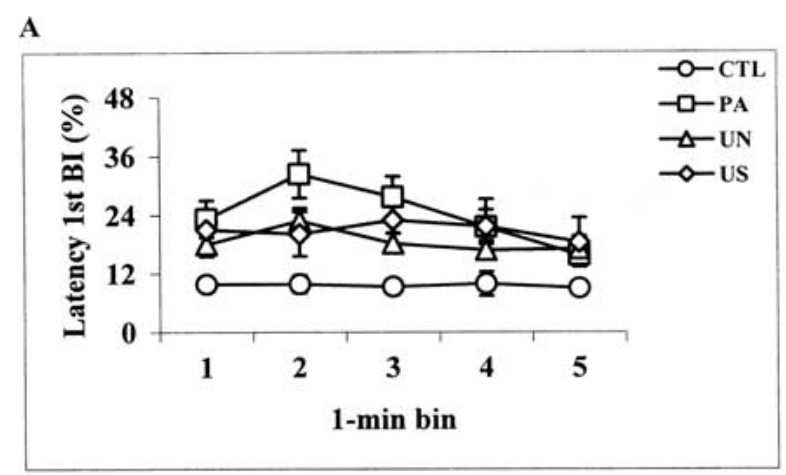

B

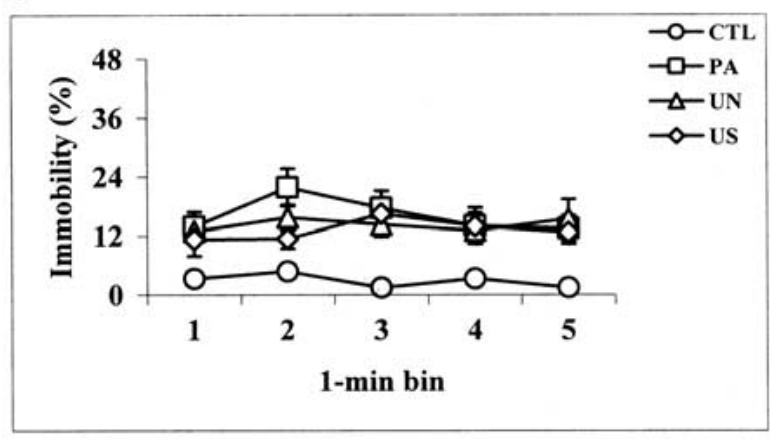

C

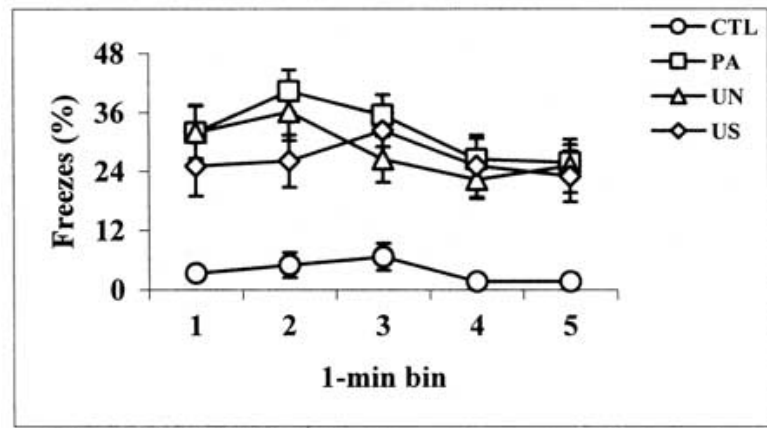

Figure 4 Context test. Percentage of immobility displayed by control (CTL, $n=10$ ), paired (PA, $n=12)$, unpaired ( $U N, n=12)$, and US exposure only (US, $\mathrm{n}=8$ ) mice during consecutive 1 -min time intervals as assessed by latency $1 \mathrm{st} \mathrm{BI}(A)$ and the continuous $(B)$ and time-sampling $(C)$ methods of hand scoring. Both hand-scored and latency $1 \mathrm{st} \mathrm{BI}$ data revealed that throughout the 5 min context test, PA, UN, and US mice displayed higher levels of freezing behavior than the CTL group $(P<.005$, Newman-Keuls post hoc test).

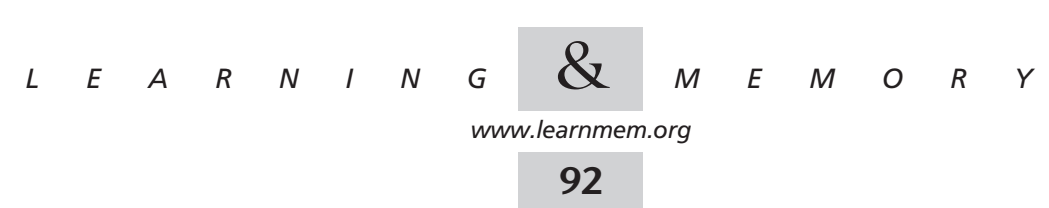


$P<.005)$. Post hoc comparisons showed that during the 6-min CS test sessions, PA, UN, and US mice spent more time immobile than CTL mice $(P<.05)$; overall, no difference was observed among the PA, UN, and US groups. However, during the 4th min, PA mice showed higher levels of immobility than UN, US, and CTL mice $(P<.005$; Fig. 5A). Analogous results were obtained with latency 2 nd and $3 \mathrm{rd}$ BI parameters (data not shown). In contrast, analysis of BI results revealed a group effect $(F[3,38]=10.10, P<.0001)$, a time effect $(F[5,190]=44.25, P<.0001)$, but no group $\times$ time interaction effect $(F[15,190]=1.51, P=0.10$; data not shown). Continuous hand-scored data revealed a group effect $(F[3,38]=7.62, \quad P<.0005), \quad$ an effect of time $(F[5,190]=28.7, P<.0001)$, and a group $\times$ time interaction effect $(F[15,190]=3.06, P<.0005)$. Throughout the CS test, PA, UN, and US mice spent more time immobile than CTL mice $(P<.05)$. Moreover, after presentation of the CS, during the 4th min of the CS test, higher levels of immobility behavior were observed in PA mice compared with UN, US, and CTL mice $(P<.0001$; Fig. 5B). Last, time-sampling hand-scored data revealed a group effect $(F[3,38]=13.99$, $P<.0001)$, an effect of time $(F[5,190]=16.06, P<.0001)$, and a group $\times$ time interaction effect $(F[15,190]=2.78$, $P<.001)$. Overall, PA, UN, and US mice spent more time freezing than CTL mice $(P<.005)$; however, during the 4 th min of the CS test, higher levels of freezing behavior were observed in PA mice compared with UN, US, and CTL mice $(P<.0001$; Fig. 5C). Thus, experimenter and automated parameters of scoring were able to detect increased levels of immobility in response to an auditory tone (CS) only in mice trained to associate the CS with the US. In addition, automated scoring provided behavioral patterns very similar to those obtained with the visual observation methods. In particular, during the initial $3 \mathrm{~min}$ of the CS test (pre-CS), higher levels of immobility behavior in response to environmental stimuli modified from those previously paired with the US were observed in mice exposed to the US during conditioning sessions compared with mice never treated with the US (contextual fear generalization; see Fig. 5).

\section{DISCUSSION}

The present study examined the ability of a computer-controlled Freeze Monitor system to detect immobility behavior in mice during fear conditioning experiments. Data collected by a trained experimenter were compared with immobility scores obtained with the automated apparatus. Statistical analyses revealed significant correlations between hand-scored results obtained with two different methods of data collection and results derived from automated scoring. Moreover, throughout the different experimental phases, similar behavioral patterns were obtained from the automated procedure and the hand-scored data. Correlations and goodness-of-fit measured by $r^{2}$ values were improved with increased amounts of freezing and weakest under con-

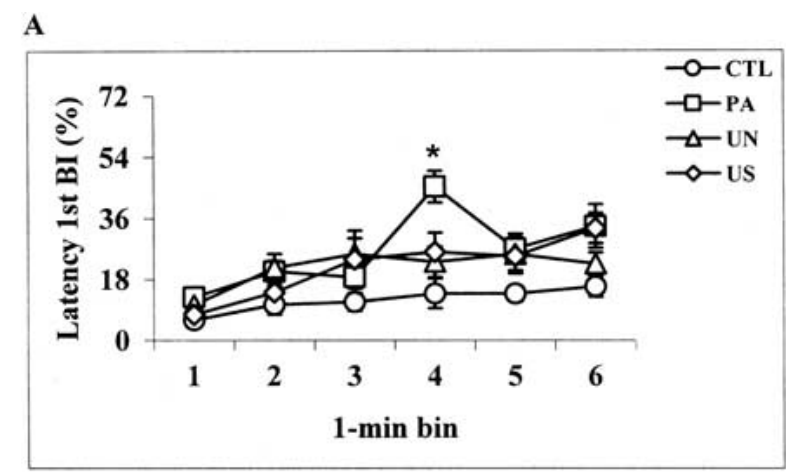

B

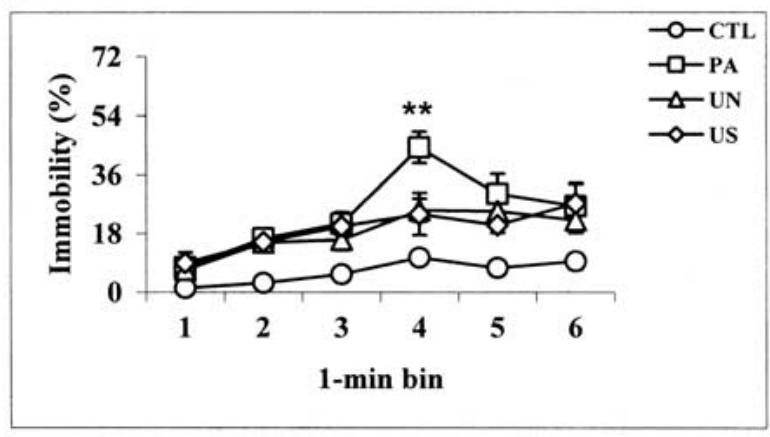

C

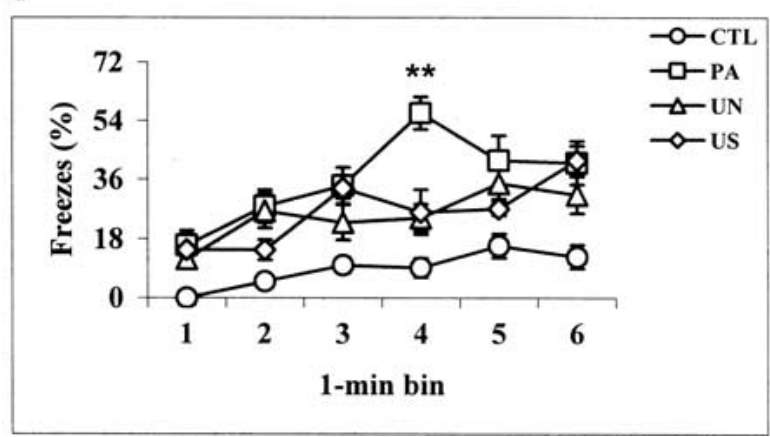

Figure 5 CS test. Percentage of immobility displayed by control (CTL, $n=10$ ), paired (PA, $n=12$ ), unpaired (UN, $n=12)$, and US exposure only (US, $n=8$ ) mice during consecutive 1 -min time intervals as assessed by latency $1 \mathrm{st} \mathrm{BI}(A)$ and the continuous $(B)$ and time-sampling $(C)$ methods of hand scoring. The auditory CS was administered during the last $3 \mathrm{~min}$ (4th to 6th) of CS testing. Both hand-scored and latency 1 st $\mathrm{BI}$ results indicated that during the 4th min of CS testing, PA mice showed increased levels of freezing behavior compared with UN, US, and CTL groups. ${ }^{*} P<.005,{ }^{*} P<.0001$ versus $\mathrm{UN}, \mathrm{US}$, and CTL mice at the same time point (Newman-Keuls post hoc test).

ditions of very low freezing (eg., CTL group compared with PA group and pre-CS compared with context or CS periods).

By use of the Freeze Monitor system described here, Valentinuzzi et al. (1998) showed the ability of this auto-

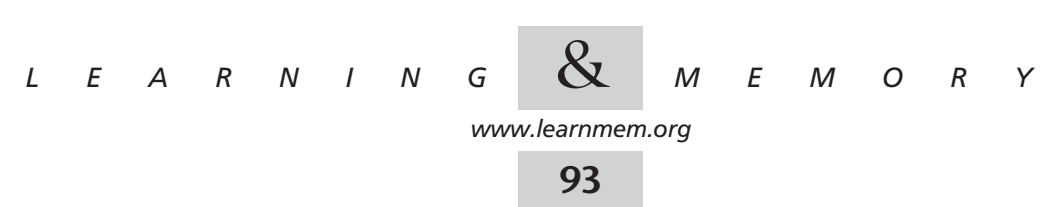


mated fear conditioning apparatus to detect increased freezing responses in mice exposed to environmental (contextual) stimuli previously paired to a mild foot shock (US). To extend the validation of the automated system and to control for specificity of responses to contextual and discrete cue stimuli, the present work examined context and cued fear responses of various groups of mice exposed to CS and US with slightly different training protocols. The results obtained showed that the automated scoring was in fact able to detect differences between mice in which a discrete auditory tone (CS) was paired with a mild foot shock (US) and mice exposed to both CS and US stimuli but in an unpaired fashion. Noteworthy, these group differences were produced by application of a relatively short time interval $(40 \mathrm{sec}$ ) between presentation of the CS and US during conditioning of the unpaired group. Nevertheless, during CS testing both hand-scored results and computer-derived data detected increased levels of immobility in response to the auditory cue only in the mice trained to associate the CS to the US (paired group). Furthermore, analysis of experimenter- and computer-derived data revealed that during the CS test higher levels of immobility displayed by the paired group started with the onset of the CS (4th min of testing) and lasted for about $1 \mathrm{~min}$. These results clearly indicate conditioning in mice given a single pairing of the US with a discrete CS. This form of associative learning could be detected by both hand-scored and automated results despite all groups with exposure to the US during conditioning sessions (PA, UN, and US mice) showing high levels of freezing throughout CS test sessions. The mouse strain used here (C57BL/6) has been shown to exhibit high levels of freezing behavior when exposed to testing chambers with environmental features much different from those associated with a foot-shock US (Logue et al. 1997; Gerlai 1998). This behavior, which may reflect the animal's ability to associate particularly salient stimuli and/ or experimental procedures with the aversive US, is often referred to as "contextual fear generalization" (Radulovic et al. 1998; Milanovic et al. 1998). During CS testing, both hand-scored and computerized data revealed comparable levels of contextual fear generalization. The similarity between behavioral patterns recorded by visual observation and the automated procedure further supports the validity of immobility scores obtained with the Freeze Monitor.

Automated scoring of mouse behavior by multiple parameters (latency to and number of $\mathrm{BI}$ ) provided results difficult to obtain by the visual observation method. Particularly, during the initial part of the conditioning sessions mice displayed an intense exploratory activity. Both handscored data and latency BI results collected during this experimental phase showed near-zero levels of immobility behavior, which made it difficult to carry out group comparisons. Similar findings were reported by Valentinuzzi et al. (1998) who showed that latency BI may not be very sensi- tive measures to assess freezing behavior of mice showing very low levels of immobility. Throughout the experiments performed here, a number of BI were also collected by the Freeze Monitor system. Unlike latency $\mathrm{BI}$, analysis of the number of $\mathrm{BI}$ allowed a more precise evaluation of ambulatory activity levels displayed by mice in response to the novel environment of the conditioning chamber. In the present study, no group differences were observed during the first minute of the conditioning sessions. However, analysis of BI data obtained during a parallel study revealed significant genotype-dependent group differences in levels of unconditioned ambulatory activity that were not detected by latency BI parameters (Contarino et al. unpubl. observations). Thus, among the automated parameters provided by the Freeze Monitor system, BI scores may be used to reliably quantify levels of ambulation in mice on initial exposure to the conditioning chamber. Baseline levels of locomotor activity should always be assessed in mice tested for learning and memory abilities with the fear conditioning paradigm, especially in the case of studies examining the outcome of genetic mutations that might alter ambulatory activity and thus affect freezing performance. Furthermore, unlike latency BI results, BI data collected during the final $30 \mathrm{sec}$ of the conditioning sessions revealed the effect of US exposure. Freezing responses displayed immediately after footshock exposure have been suggested to reflect both conditional and unconditional reactions to the US and to depend on anatomical structures different from those involved in long-term contextual fear (Fanselow 1986; 1990; Kim et al. 1992; 1993). Here, after US exposure, mice made significantly less BI than control mice. However, US-treated mice also displayed frequent head movements that may have caused BI of near photobeams, thus producing latency BI values similar to those observed in control mice. This peculiar behavior was not observed during context test sessions.

The automated procedure described here possesses several advantages over more traditional methods of scoring by direct observation or from videos. CS and US characteristics (frequency, intensity, and time of delivery) are controlled by computer software, thus allowing a more precise control over the exposure of different animals to conditioned and unconditioned stimuli. Moreover, apart from being far less labor intensive than observation-based methods of scoring, automated systems can provide the experimenter with additional behavioral indices, such as levels of ambulatory activity, which are difficult to measure with observation procedures of scoring.

In conclusion, the experiments shown here demonstrate the ability of a computerized Freeze Monitor system to reliably record conditioned fear responses of mice. Multiple automated parameters were in fact able to detect contextual and cued fear conditioning in mice previously trained with an aversive US. Overall, patterns of immobility

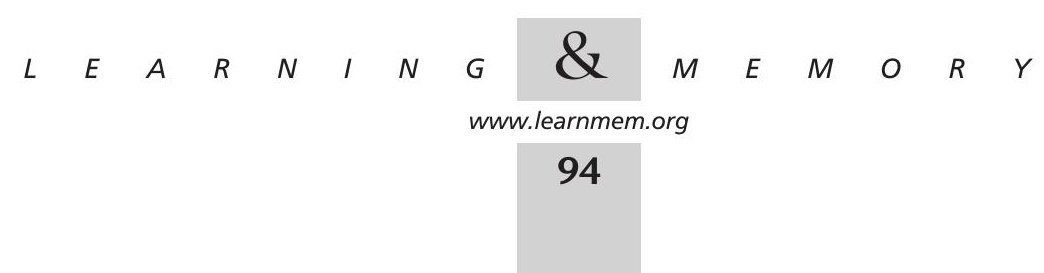


behavior recorded by the automated procedure closely resembled those detected by a trained experimenter. Prior studies have shown the effectiveness of different automated systems to detect effects of mouse and rat strain differences (Valentinuzzi et al. 1998; Richmond et al. 1998), shock intensity, hippocampal lesions, and tone preexposure (latent inhibition) on contextual and auditory cue fear conditioning (Richmond et al. 1998; Anagnostaras et al. 2000). The present study extends these prior findings by showing that the Freeze Monitor apparatus used here can detect the effect of additional important experimental manipulations. In particular, automated parameters reliably detected contextual fear generalization behaviors as well as levels of immobility caused by habituation processes and group differences caused by slightly different training protocols (e.g., CS performance of paired and unpaired groups). Moreover, findings of significant correlations between automated and experimenter derived data collected with two considerably different methods of hand scoring, that is, continuous and time-sampling, further support the validity of the behavioral scores obtained with the Freeze Monitor system. The increasing availability of genetically engineered mice pose many laboratories with the need to use experimental paradigms adapted for use in mice. The automated fear conditioning procedure described here is likely to prove very useful in the study of learning and memory processes in the mouse.

\section{MATERIALS AND METHODS}

\section{Subjects}

Male mice C57BL/6J obtained from The Scripps Research Institute breeding colony were used for the experiments at the age of 3-4 mo. Before the experiments, the animals were allowed a $15-\mathrm{d}$ acclimatization period during which they were handled two to three times a week. They were group-housed in a colony room maintained under conditions of a regular light/dark cycle (lights on 6 a.m., lights off 6 p.m.) at a temperature of $22^{\circ} \mathrm{C}$. Food and water were available ad libitum. Experiments were performed during the light phase of the light/dark cycle. All studies were conducted in accordance with the Guide for the Care and Use of Laboratory Animals and were approved by the Institutional Animal Care and Use Committee of The Scripps Research Institute.

\section{Apparatus}

The fear-conditioning apparatus consisted of a transparent acrylic chamber measuring $25 \mathrm{~cm}$ wide, $18 \mathrm{~cm}$ high, and $21 \mathrm{~cm}$ deep (San Diego Instruments). The floor was made of stainless steel rods and was connected to a shock generator (San Diego Instruments). The chamber was surrounded by a frame with 16 infrared photo beams. A computer controlled the administration of the foot shock (US) and auditory tone (CS) and recorded beam interruptions (BI) and latencies to beam interruptions (latency BI). The conditioning chamber and surrounding frame were located inside a sound-attenuated enclosure (dimensions: $56 \mathrm{~cm}$ wide $\times 38 \mathrm{~cm}$ high $\times 36 \mathrm{~cm}$ deep). A 15-W lightbulb and a small fan were located on two different side walls of the enclosure. A speaker placed on a side wall of the conditioning chamber served to deliver the auditory tone (CS).

\section{Experimental Design}

\section{Conditioning Sessions}

Mice were brought to a room adjacent to the experimental room 1 $\mathrm{h}$ before the start of the experiments. They were randomly assigned to four different groups designated as paired (PA), unpaired (UN), US exposure only (US), and no stimuli (CTL). On the training day, mice were placed in the test chamber and allowed to freely explore it for a 3-min time period. For mice in the PA group, an auditory tone $(\mathrm{CS} ; 3000 \mathrm{~Hz}, 80 \mathrm{~dB})$ was presented $120 \mathrm{sec}$ after the session started. It lasted $30 \mathrm{sec}$ and terminated with the presentation of the foot shock (US; $2 \mathrm{sec}, 0.7 \mathrm{~mA}$ ). For mice in the UN group, the CS was presented $80 \mathrm{sec}$ after the session started and lasted $30 \mathrm{sec}$. After the CS was terminated, a 40-sec time interval was allowed to elapse before the presentation of the US. Mice in the US group were exposed only to the foot shock, which occurred at the same time as for the PA and UN groups, but no CS was presented. Finally, mice in the CTL group were placed in the testing chamber without being exposed to either the auditory tone or to the US. Mice were removed from the conditioning chamber $30 \mathrm{sec}$ after the termination of the US (Fig. 1).

\section{Context and CS Test}

Twenty-four hours after the conditioning session, mice were placed in the test chamber and their behavior scored for 5 min (context test). Approximately $1 \mathrm{~h}$ after the context test, mice were tested for freezing responses to the CS. For this purpose, the conditioning chamber was altered by placing a smooth floor on top of the grid floor and dividing the chamber in half by inserting a black plastic panel $(32 \mathrm{~cm}$ wide $\times 18 \mathrm{~cm}$ high) connecting the diagonal corners. During the CS test, mice were left in the altered chamber for $6 \mathrm{~min}$, with the auditory tone being presented during the last $3 \mathrm{~min}$.

\section{Behavioral Scoring}

Throughout conditioning and the context and CS tests, mouse behavior was recorded onto videotape through a recorder placed in a room adjacent to the experimental room and connected to a microcamera placed $13 \mathrm{~cm}$ above the clear Plexiglas top of the conditioning chamber. Conditioning and test sessions were later scored by a trained experimenter who was unaware of the experimental group to which the mice had been assigned. Two different methods of hand scoring were adopted: (1) continuous recording of the time mice spent immobile, and (2) time-sampling measurement of freezing behavior, that is, every $5 \mathrm{sec}$ each mouse was judged as either freezing or active. Freezing was defined as the absence of visible movement, except for respiration. In addition, four automated indices of immobility behavior were obtained from the Freeze Monitor system. These included the number of BI and the time latency to break the first (latency 1st BI), second (latency 2nd BI), and third (latency 3rd BI) new photo beam in each 5-sec interval. In particular, test sessions were divided into 5 -sec intervals and the time elapsed between the beginning of each 5-sec interval and interruption of the first three new photo beams was recorded. If no BI occurred during the 5 -sec interval, a score of $5 \mathrm{sec}$ was recorded. For illustration purposes, the percentage of time spent immobile (latency 1st BI and continuous hand scoring) and of freezing episodes (time-sampling hand scoring) during consecutive 30sec (conditioning sessions) or 1-min (context and CS tests) time intervals are shown.

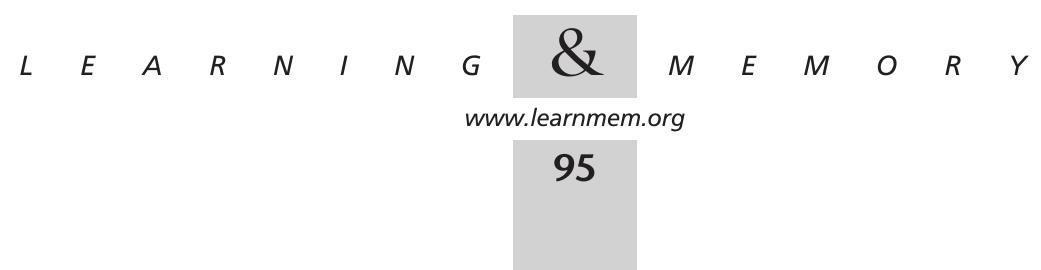




\section{Statistical Analysis}

Freezing scores recorded by the experimenter were compared with the different automated measures provided by the Freeze Monitor system (latency 1st, 2nd, 3rd BI and number of BI) with Pearson's correlation (Microsoft Excel 2000) and linear regression (GraphPad Prism 3.0, San Diego, CA) analyses. For this purpose, immobility responses displayed by each mouse during the context test $(5 \mathrm{~min})$ and the two phases of the CS test (the 3-min time period preceding or following the onset of the auditory tone, designated as pre-CS and CS, respectively) were used. Levels of unconditioned ambulatory activity displayed by the four experimental groups were examined by one-way analysis of variance (ANOVA) performed on the total number of $\mathrm{BI}$ made during the first minute of exposure to the conditioning chamber. Immobility levels after US delivery were analyzed by one-way ANOVAs performed on hand-scored and automated results collected during the final $30 \mathrm{sec}$ of the conditioning sessions. Behavioral performance during context and CS tests was evaluated by two-way ANOVAs with the group (PA, UN, US, and CTL) as the between-subject factor and immobility scores collected during consecutive 1-min time intervals as the within-subject factor. Finally, hand-scored and automated results (mean value/minute) derived from the CTL group during conditioning and context test sessions were compared by use of the paired $t$ test. Post hoc group comparisons were performed with the Newman-Keuls test. The accepted value of significance was $P<.05$. Although data are presented as percent values, statistical analyses were performed on the absolute values of immobility time (latencies BI and continuous hand scores) and the number of BI and freezes (time-sampling hand scores).

\section{ACKNOWLEDGMENTS}

This is publication 14226-NP from The Scripps Research Institute. This work was supported by the grant MH47680.

The publication costs of this article were defrayed in part by payment of page charges. This article must therefore be hereby marked "advertisement" in accordance with 18 USC section 1734 solely to indicate this fact.

\section{REFERENCES}

Abeliovich, A., Paylor, R., Chen, C., Kim, J.J., Wehner, J.M., and Tonegawa, S. 1993. PKC gamma mutant mice exhibit mild deficits in spatial and contextual learning. Cell 75: 1263-1271.

Aiba, A., Chen, C., Herrup, K., Rosenmund, C., Stevens, C.F., and Tonegawa, S. 1994. Reduced hippocampal long-term potentiation and context-specific deficit in associative learning in mGluR1 mutant mice Cell 79: 365-375.

Anagnostaras, S.G., Josselyn, S.A., Frankland, P.W., and Silva, A.J. 2000. Computer-assisted behavioral assessment of Pavlovian fear conditioning in mice. Learn. Mem. 7: 58-72.

Bourtchuladze, R., Frenguelli, B., Blendy, J., Cioffi, D., Schutz, G., and Silva, A.J. 1994. Deficient long-term memory in mice with a targeted mutation of the cAMP-responsive element-binding protein. Cell 79: 59-68

Crawley, J.N., Belknap, J.K., Collins, A., Crabbe, J.C., Frankel, W., Henderson, N., Hitzemann R.J., Maxson, S.C., Miner, L.L., Silva, A.J., et al. 1997. Behavioral phenotypes of inbred mouse strains: implications and recommendations for molecular studies. Psychopharmacology (Berl) 132: 107-124
Fanselow, M.S. 1986. Associative vs. topographical accounts of the immediate shock freezing deficit in rats: Implications for the response selection rules governing species specific defensive reactions. Learn. Motiv. 17: 16-39.

- 1990. Factors governing one-trial contextual conditioning. Anim. Learn. Behav. 18: 264-270.

-2000. Contextual fear, gestalt memories, and the hippocampus. Behav. Brain Res. 110: 73-81.

Gerlai, R. 1998. Contextual learning and cue association in fear conditioning in mice: A strain comparison and a lesion study. Behav. Brain Res. 95: 191-203.

Gold, L.H. 1996. Integration of molecular biological techniques and behavioural pharmacology. Behav. Pharmacol. 7: 589-615.

Kim, J.J., Fanselow, M.S., DeCola, J.P., and Landeira-Fernandez, J. 1992. Selective impairment of long-term but not short-term conditional fear by the N-methyl-D-aspartate antagonist APV. Behav. Neurosci. 106: 591-596.

Kim, J.J., Rison, R.A., and Fanselow, M.S. 1993. Effects of amygdala, hippocampus, and periaqueductal gray lesions on short- and long-term contextual fear. Behav. Neurosci. 107: 1093-1098.

Logue, S.F., Paylor, R., and Wehner, J.M. 1997. Hippocampal lesions cause learning deficits in inbred mice in the Morris water maze and conditioned-fear task. Behav. Neurosci. 111: 104-113.

LoLordo, V.M. and Ross, R.T. 1990. Retraction of Ross and LoLordo findings concerning blocking in serial feature-positive discriminations. J. Exp. Psychol. Anim. Behav. Process 16: 402-406.

Milanovic, S., Radulovic, J., Laban, O., Stiedl, O., Henn, F., and Spiess, J. 1998. Production of the Fos protein after contextual fear conditioning of C57BL/6N mice. Brain Res. 784: 37-47.

Owen, E.H., Logue, S.F., Rasmussen, D.L., and Wehner, J.M. 1997. Assessment of learning by the Morris water task and fear conditioning in inbred mouse strains and F1 hybrids: Implications of genetic background for single gene mutations and quantitative trait loci analyses. Neuroscience 80: 1087-1099.

Phillips, R.G. and LeDoux, J.E. 1992. Differential contribution of amygdala and hippocampus to cued and contextual fear conditioning. Behav. Neurosci. 106: 274-285.

Radulovic, J., Kammermeier, J., and Spiess, J. 1998. Generalization of fear responses in $\mathrm{C} 57 \mathrm{BL} / 6 \mathrm{~N}$ mice subjected to one-trial foreground contextual fear conditioning. Behav. Brain Res. 95: 179-189.

Richmond, M.A., Murphy, C.A., Pouzet, B., Schmid, P., Rawlins, J.N., and Feldon, J. 1998. A computer controlled analysis of freezing behaviour. J. Neurosci. Methods 86: 91-99.

Sanberg, P.R., Moran, T.H., Kubos, K.L., and Coyle, J.T. 1984. Automated measurement of rearing behavior in adult and neonatal rats. Behav. Neurosci. 98: 743-746.

Sanberg, P.R., Hagenmeyer, S.H., and Henault, M.A. 1985. Automated measurement of multivariate locomotor behavior in rodents. Neurobehav. Toxicol. Teratol. 7: 87-94.

Silva, A.J., Smith, A.M., and Giese, K.P. 1997. Gene targeting and the biology of learning and memory. Annu. Rev. Genet. 31: 527-546.

Valentinuzzi, V.S., Kolker, D.E., Vitaterna, M.H., Shimomura, K., Whiteley, A., Low-Zeddies S., Turek, F.W., Ferrari, E.A., Paylor, R., and Takahashi, J.S. 1998. Automated measurement of mouse freezing behavior and its use for quantitative trait locus analysis of contextual fear conditioning in (BALB/CJ x C57BL/6J)F2 mice. Learn. Mem. 5: 391-403.

Wehner, J.M. and Silva, A. 1996. Importance of strain differences in evaluation of learning and memory processes in null mutants. Ment. Retard. Dev. Disabil. Res. Rev. 2: 243-248.

Received July 2, 2001; accepted in revised form March 7, 2002.

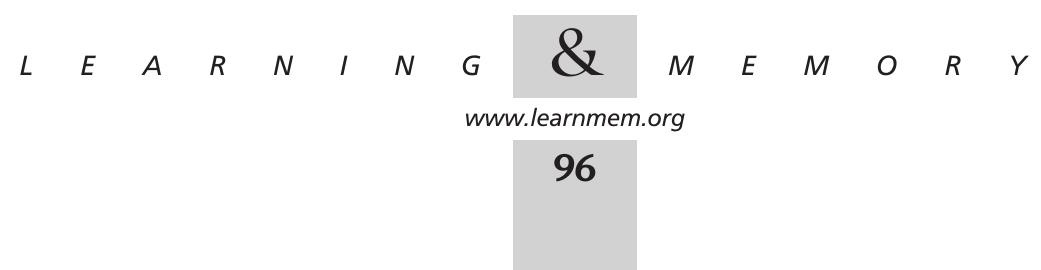




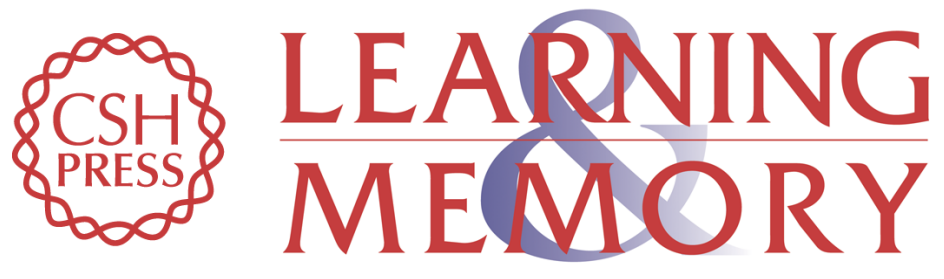

\section{Automated Assessment of Conditioning Parameters for Context and Cued Fear in Mice}

Angelo Contarino, Leonardo Baca, Arthur Kennelly, et al.

Learn. Mem. 2002, 9:

Access the most recent version at doi:10.1101/lm.43002

References This article cites 23 articles, 2 of which can be accessed free at: http://learnmem.cshlp.org/content/9/2/89.full.html\#ref-list-1

License

Email Alerting Receive free email alerts when new articles cite this article - sign up in the box at the Service top right corner of the article or click here. 